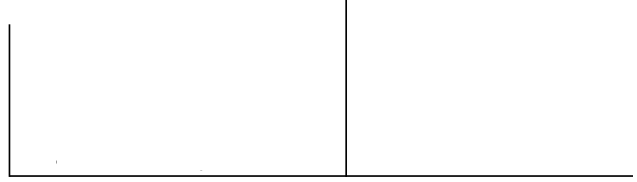

Rev. Latinoam. Psicopat. Fund., V, 2, 150-158

O sorriso da Gioconda - Clínica psicanalítica com os bebês prematuros

Catherine Mathelin

Rio de Janeiro: Companhia de Freud, 1999

\title{
O pau na boca do jacaré
}

\section{Veridiana Fráguas}

O livro inicia com o relato da cena de um garoto de cinco anos no Museu do Louvre, Paris, acompanhado de sua mãe. Assustado diante da imagem da Gioconda, ele lhe pergunta: "Mamãe, o que é que a moça está querendo?”.

A autora nos chama a atenção para algo implícito na pergunta do garoto, que seria a seguinte questão: “O que ela está querendo de mim?”. Esta cena é utilizada para introduzir a questão da captura da criança pelo desejo da mãe, tema que será discutido ao longo de todo o livro.

Logo nas primeiras páginas, a autora destaca o momento desta captura da criança pelo olhar da mãe, como fundador de seu aparelho psíquico: “É na relação com ela (mãe) que o pequenino descobrirá seu corpo e as emoções que este corpo proporciona. É com ela, capturado em seu olhar, que ele se olhará, é carregado por suas palavras que pensará” (p. 10).

Ela nos chama a atenção para o quanto esta captura, se não sofre o corte de uma função paterna - ou seja, a entrada de um terceiro na relação - pode ser alienante e enlouquecedora para a criança. O desejo da mãe, de manter a criança nesta captura, é simbolizado pelo sorriso da Gioconda, ambivalente em si mesmo quando exprime tanto a promessa de uma felicidade plena a dois, como a proibição do acesso à felicidade proporcionada pela relação com outros objetos de amor. Seria a representação de uma espécie de "possessão devastadora”, tornando o sorriso da Gioconda inquietante, à medida que exprime a idéia de que, por amor, se mata e se engole. 
A autora introduz, desta forma, o tema que pretende desenvolver a partir de seu trabalho como analista, dentro de um serviço de reanimação neonatal num hospital em Saint-Denis.

Usando desta metáfora do sorriso da Gioconda, se propõe a discutir a relação entre bebês prematuros e suas mães. Tomando esta peculiaridade dos bebês nascidos prematuramente, mostra como a captura pelo desejo da mãe pode ter conseqüências avassaladoras para a criança. Destaca, então, a função que teria o serviço de neonatologia nestes casos: uma função paterna.

Coloca que uma das principais questões com as quais estas mães se defrontam é a ambivalência em relação a seus bebês, questão evocada inevitavelmente quando se trata do tema da maternidade. Não existe maternidade sem ambivalência, assim como não existem relações humanas sem ambivalência: “A maternidade não é um conto de fadas e o traumatismo da hospitalização nos lembra disso" (p. 29).

Nestes casos, é como se a realidade reencontrasse o fantasma da ambivalência, trazendo intensos sentimentos de culpa de ser uma "mãe má" que não pôde carregar seu filho, talvez por ter desejado, em algum momento, a sua morte.

No momento em que a mãe se depara com esta situação que provoca intensos sentimentos de culpa, de fracasso e de raiva, a melhor medida é que seu bebê fique aos cuidados da equipe médica. Poupa-se, assim, mãe e bebê - durante algum tempo - de uma convivência muito turbulenta que poderia ser prejudicial a ambos. Como diz a autora, neste momento a equipe médica teria a função (paterna) de impedir que mãe e criança se “devorem” uma a outra.

A equipe médica, por sua vez, tem que lidar com uma contradição muito difícil: como entender desejos destrutivos da mãe em relação a um bebê que eles se esforçaram tanto para salvar? Ou ainda, como renunciar às idéias prontas sobre o amor idealizado das mães? Uma das maiores dificuldades que a autora destaca neste trabalho, decorre da necessidade da equipe de médicos e de enfermeiros em preservar para si a imagem da mãe como uma figura terna e amorosa em relação ao seu filho.

Diante dos efeitos da inevitável transferência que se estabelece entre equipe médica e pacientes, o analista procura trabalhar este aspecto junto a equipe.

Um dos pilares de seu trabalho dentro deste serviço é a quebra do mito da "boa mãe”, sempre doce e amável com o filho. Além disso, procura não tratar o parto prematuro necessariamente como um sintoma. Ela desmistifica a idéia de que a criança prematura não foi desejada pelos pais. A questão é que geralmente foi muito desejada, mas se pergunta que lugar ela ocupa no desejo deles.

O que observa em sua clínica, e isso sim ela afirma, é que: “(...) em quase todas as histórias de nascimento difícil, as relações entre as mães e sua própria mãe foram dolorosas” (p. 87).

Dentro daquilo que lhe cabe afirmar, ela coloca que a psicanálise traz a seguinte questão dentro de um serviço de neonatologia: a fala tem poder sobre o corpo. 
Partindo deste ponto de vista, vai trabalhar com a questão do desejo e do fantasma, levantando situações onde a criança fica presa a uma armadilha do discurso materno a ponto de isso ser fatal para ela. O relato de uma série de casos que acompanhou no serviço de reanimação neonatal ilustram este poder da fala sobre o corpo. E conclui: "É preciso também, para viver, inscrever-se numa fala, senão o ser humano morre" (p. 23).

Por outro lado, relata situações em que, a partir de um trabalho conjunto da equipe e do psicanalista, foi possível para algumas mães retomar suas histórias e seus fantasmas, libertando seus filhos da cadeia da repetição.

Ao abordar o tema do trabalho analítico dentro de um serviço de reanimação neonatal a autora coloca que, do ponto de vista psicanalítico, a "reanimação" consistiria em reanimar a criança e o discurso que a anima, restabelecendo nos pais a capacidade de amar seus filhos e, no bebê, seu desejo de viver.

Traz uma idéia inovadora que diz respeito a uma co-responsabilidade entre reanimadores e psicanalistas num serviço de neonatologia. Partindo disso, o trabalho seria implementado em vários níveis: com a criança, com os pais e com a equipe.

\section{O trabalho com a criança}

A autora propõe, como premissa deste trabalho, a possibilidade de olhar para a criança enquanto um pequeno sujeito, com uma história da qual a sua permanência na neonatologia seria apenas um episódio. Coloca a importância de conversar com estes bebês a respeito de suas histórias, dos cuidados médicos aos quais estão sendo submetidos e das razões de sua hospitalização.

Seria fundamental que todas as pessoas envolvidas neste trabalho pudessem “deixar-se tocar” pela criança, e não falar mecanicamente com ela só porque sabemos que isso é importante. Destaca a importância de uma "fala verdadeira", que não negue o sofrimento decorrente dos cuidados dolorosos aos quais estão sendo submetidas, e que elas têm todo o direito de sentirem como maus-tratos.

Pode-se perguntar até que ponto um ser tão frágil pode apreender algo do que falamos com ele. Em resposta a esta questão, a autora nos chama a atenção para um fato comprovado por pesquisas científicas: o bebê é sensível à voz, à fala e ao afeto veiculado pela linguagem. Ele identifica a voz da mãe, familiar a ele desde o útero, e reage diferentemente aos seus estados de ânimo. Estão sempre "a pedir sentido", são "vigias alegres, (...) sempre à espreita da presença do outro” (p. 37).

Nos casos em que tudo corre bem entre mãe e bebê existe, de antemão, a suposição de que o bebê é capaz de responder às tentativas de nos comunicarmos com ele. Se tal suposição se faz presente, isso revela que houve um investimento narcísico dos pais naquela criança. E é justamente este narcisismo que vai ser 
colocado a uma dura prova quando os pais se defrontarem com a realidade do bebê prematuro.

\section{O trabalho com os pais}

O trabalho junto aos pais começa no momento em que a criança entra na unidade. Eles fazem uma consulta com o médico responsável, uma entrevista com o psicanalista e passam a ser atendidos sistematicamente, junto com a criança.

Nas entrevistas com o psicanalista, os pais podem falar de sua angústia e do traumatismo que representa esse encontro com o real. $\mathrm{O}$ trabalho visa fazer com que a criança não se torne, para eles, um mero "pedaço de carne" a ser reanimado.

A criança prematura, magra e fraca, corre o risco de passar a ser vista como puro real. A mãe não se reconhece no filho que, por sua vez, não pode se reconhecer nela. Diz a autora: "Como investir um filho que ela sente monstruoso e perseguidor, um filho que lhe significa sua impotência e seu fracasso?” (p. 25).

O parto prematuro, assim como qualquer situação de urgência, traz consigo uma experiência de violência: o bebê é tirado rapidamente dos braços da mãe e os médicos lhe dizem que não sabem se ele sobreviverá. Vida e morte ficam muito próximas; angústia e culpa ficam muito presentes. O bebê, extremamente frágil e pouco responsivo, falta ao encontro da reparação. Nas palavras de Mathelin: "O real em todo seu horror conduz o jogo" (p.67).

As mães passam, então, por um sentimento de "irrealidade”. O filho é realmente seu? Saiu de seu ventre? Estamos diante de uma situação peculiar, como se a gestação terminasse "fora da barriga", daí o sentimento de irrealidade.

Com o nascimento ocorrendo prematuramente, a mãe fica privada do período final da gravidez em que o bebê começa a mexer e a responder a estímulos. É quando ela começa a "sonhar" seu filho, construindo uma imagem dele para si. É também o momento em que socialmente é reconhecida como mãe.

Diante da impossibilidade desse tempo de elaboração indispensável para se construir mãe e bebê, a falicização da criança fica seriamente comprometida. Mathelin nota uma grande dificuldade destas mães em olhar para seus bebês, falar-lhes, darlhes um nome. Ocorre um desencontro entre mãe e bebê, onde a mãe desvia seu olhar da criança e esta, por sua vez, está fraca demais para mostrar seu interesse por ela: “O que ali está em sofrimento é a possibilidade de investimento libidinal da mãe. Como colocar esse bebê num lugar de ideal onde a falicização seria possível?” (p. 25).

Em outras palavras, como tornar o filho criador de mãe?

A isso vem se somar a separação mãe/bebê durante o período em que a criança está na encubadora - um a-mais que reatualiza angústias de separação que não puderam ser simbolizadas. 
R E V I S

LATINOAMERICANA

DE PSICOPATOLOGIA

F U N D A M E T A L

ano V, n. 2, jun/ 2002

Como nos coloca Mathelin, cabe ao psicanalista criar um espaço para que essas mães possam fazer um trabalho de luto, de perda e de separação. A partir do momento em que elas puderem simbolizar esta falta, poderão deslocar o filho deste "puro real" e projetar sobre ele um futuro.

\section{O trabalho com a equipe}

Uma das peculiaridades do trabalho do psicanalista junto à equipe é que, ao mesmo tempo, ele é parte integrante da mesma. Qual seria, então, o seu lugar dentro da equipe?

A autora coloca que o psicanalista no hospital teria um papel semelhante ao do psicanalista de rua. Num serviço de medicina, o lugar do analista deve ser "flutuante e maleável”, sempre pronto a ser reinventado. Não há como negar que está dentro de um hospital e que é parte integrante da equipe, mas o analista deve, em alguns momentos, colocar-se de fora para poder ter uma escuta mais distanciada.

Aborda, então, algumas premissas para que o trabalho em equipe seja possível. Uma delas seria respeitar uma orientação e um projeto comuns para que, em momentos de crise, haja uma baliza para onde voltar.

Destaca também a importância de confiar nos médicos. Ela nos alerta para o risco de que, na relação com os médicos, possa ocorrer atitudes fóbicas como a evitação de contato, rivalidade, onipotência, etc. O psicanalista deve ainda deixar de lado a compreensão dos motivos inconscientes que levam os médicos a escolherem o serviço de neonatologia.

O trabalho com os médicos consistiria em propor-lhes que falem das dificuldades que encontram, fazer com que entendam uma outra abordagem da criança e da família e que fiquem atentos às transferências dentro da equipe, despertadas pela história da criança.

A autora aborda também o papel fundamental daquelas que seriam a parte da equipe que mais convive com as crianças nesse período de internação, aquelas que participam de seu dia-a-dia: as enfermeiras.

São elas que antecipam as necessidades dos bebês, são uma presença viva ao lado deles. Seu papel não seria o de meras observadoras, mas de alguém que se deixa capturar pela criança. Isso seria essencial não só na relação das enfermeiras, mas de toda a equipe com os bebês.

Coloca ainda a proposta de fazer reuniões com toda a equipe para falar sobre os bebês. Nestas reuniões, médicos, enfermeiros e o próprio psicanalista colocam quais os problemas que estão enfrentando com aquela criança e com seus pais, quais as repercussões destes problemas dentro da equipe e como a história desta criança afeta cada um deles. Estas reuniões são chamadas de sínteses. 
Ela resume, então, quais seriam as funções do analista dentro da equipe: não deixar que a equipe confunda a criança com aparelhos; falar da morte, para que não se instaure a "morte psíquica”; e fazer com que todos preservem a capacidade de pensar.

\section{Sobre o serviço de reanimação: problemas e soluções}

Mathelin coloca como principais funções do serviço de reanimação, para além dos cuidados médicos, separar mãe e criança e autorizar a mãe a exercer sua função junto ao bebê.

Esta delicada tarefa consistiria em: “... devolver um filho vivo a uma mãe que poderia acolhê-lo como enfim separado dela. Para isso é preciso que o traumatismo do nascimento possa simbolizar-se, que possa inscrever-se” (p. 10).

A autora coloca que uma das questões que se levanta a respeito do serviço de reanimação seria a seguinte: será que o hospital, ao tentar salvar a vida da criança através de longas internações, não estaria, por outro lado, “criando" crianças psicóticas? Quais os danos psíquicos destas longas internações?

Pesquisas científicas revelam o quanto o bebê prematuro sofre. Sabendo disso, os médicos procuram reproduzir o ambiente intra-uterino, como se pudessem "fingir" que o bebê ainda não nasceu. Uma espécie de denegação do fato de que a criança veio ao mundo, já que veio em condições tão precárias...

Como lidar com os fantasmas despertados por esta situação, com a imagem de um bebê esquelético, que mais parece um velho moribundo que um lactente?

Nesse sentido, torna-se essencial o trabalho do psicólogo junto aos pais e à equipe, como coloca Mathelin:

Os aparelhos, com efeito, são as ferramentas do desejo de vida dos médicos para os bebês. (...) não só a máquina terá de funcionar, mas ainda fazer parte integrante do mundo dos bebês e de seus pais. Será preciso que ele tome sentido "humano". Para isso é essencial que os pais participem do atendimento médico do bebê hospitalizado. (p. 144)

Um outro alerta que a autora nos faz diz respeito a uma atenção especial às mães durante o período de internação do bebê. Sua experiência mostra que muitas das suas dificuldades podem passar desapercebido aos nossos ouvidos, manifestando-se quando a mãe leva o bebê para casa:

Pensar que o filho ainda não nasceu ou então, na mesma recusa, considerar que já está morto participa do mesmo impulso. Estes lutos antecipados, que tornam todo investimento impossível, com frequiência são feitos baixinho. Só de volta a casa é que as complicações surgem, a mãe tendo que enfrentar um bebê vivo ao qual já renunciou para escapar a um sofrimento terrível. (p. 144) 
R E V I S

LATINOAMERICANA

DE PSICOPATOLOGIA

F U N D A M E T A L

ano $V$, n. 2, jun/ 2002

A equipe deve estar vigilante aos efeitos iatrogênicos que os cuidados com o bebê podem ter sobre os pais. Diante de todo o cuidado e do desejo da equipe em salvar a vida da criança, a mãe pode viver este período de hospitalização do bebê como uma prova concreta das acusações que se faz de ser uma "mãe má”, incapaz de cuidar de seu filho.

Um dos grandes méritos do livro é o contato com a experiência de um psicanalista dentro do hospital, com todas as dificuldades de um trabalho multidisciplinar. A autora tece observações de alguém bastante familiarizado com as inúmeras problemáticas que podem surgir nesse tipo de serviço, passando esta experiência ao leitor e propondo soluções para os problemas enfrentados no dia-adia dentro do hospital.

Um exemplo seria aquilo que ela identifica como um dos maiores problemas junto à equipe de enfermagem: como lidar com os lutos, as separações e o apego a bebês abandonados.

Uma das soluções encontradas para trabalhar esta questão junto às enfermeiras foi criar um livro onde elas escreviam mensagens de despedida para os bebês. Pode parecer algo banal, mas tinha uma função muito importante no processo de elaboração destas separações.

\section{Principais questões no trabalho com os pais}

Um problema bastante freqüente e bastante discutido nas reuniões que Mathelin fazia no hospital diz respeito à transferência que se estabelece entre a equipe e os pais. Se por um lado a presença dos pais é fundamental na recuperação dos bebês, existe também a dificuldade, por parte da equipe de médicos e enfermeiros, em trabalhar sob seus olhares.

A autora toma, por exemplo, a posição do pai, que muitas vezes é "esquecido" quando se trata de relações tão precoces. O pai se encontra numa situação muito difícil à medida que não sabe se fica junto à mãe ou ao bebê. Quem precisaria mais dele?

Nos casos de nascimentos prematuros, o pai torna-se responsável por apresentar o bebê à mãe (o oposto acontece nos casos de nascimento a termo), acompanha-a às primeiras visitas e lhe transmite com cautela as informações que recebe dos médicos.

Existem duas posições muito comuns aos pais: uma de oposição aos médicos, como uma forma de recuperarem a confiança em si mesmos, ou então identificamse com eles, interessando-se pelo tratamento, dando sua opinião, mostrando-se úteis.

Uma das principais questões no atendimento a estes pais é a grande dificuldade que surge ao se depararem com uma mãe que não consegue investir o bebê. Isso quebra sua idealização do laço mãe/filho, construído na relação com suas próprias mães. 
Nestes casos, um equívoco muito comum por parte dos pais é acharem que têm que assumir um papel de "supermães” para seus bebês, já que a mulher está incapacitada de exercer tal função. Isso pode deixar a mãe mais insegura quanto às suas possibilidades de maternagem junto à criança. $\mathrm{O}$ caso de Ludivine, descrito no livro, ilustra bem esta situação.

Voltando à questão das mães...

O capítulo final do livro é intitulado "Prematuramente mães”. Neste capítulo, a autora relata histórias de mães de crianças ex-prematuras que lhe foram encaminhadas por escolas ou por pediatras, mas que não passaram pelo serviço de reanimação para o qual trabalha. São histórias que têm como características semelhantes àquelas encontradas no serviço de neonatologia: a "prematuridade e a selvageria das forças pulsionais em ação na história de cada nascimento” (p. 117).

Este é um capítulo no qual a autora busca compreender a dinâmica psíquica presente em cada caso relatado. É o capítulo mais “teórico” do livro, onde ela dialoga com Freud, Lacan, Winnicott e Françoise Dolto, entre outros, mostrando o quanto as histórias destas mães de prematuros estão marcadas pelo que viveram enquanto filhas, com suas próprias mães. Um dado importante a ser observado nestes casos, é que estas mães normalmente se sentem vítimas de uma armadilha. Ficam desatinadas pela fatalidade daquele nascimento prematuro mas, ao mesmo tempo, têm a convicção de que não poderia ser de outra maneira. Esta convicção seria decorrente de determinadas marcas significantes na história de cada uma delas, na forma de falas mortíferas que têm peso de prescrição de destino para suas crianças.

O processo terapêutico com estas mães consistiu em situar o que a prematuridade do filho evocava em suas histórias, o que possibilitou a elas se livrarem do que sentiam como uma "maldição".

Um aspecto importante e bastante comum nas histórias das mães de prematuros seria a experiência de separação de suas próprias mães, de tal ordem que tornava a vivência de separação prematura do filho algo terrível. Em geral, são mulheres que tiveram a experiência de uma presença materna excessiva nos primórdios de suas vidas, com uma demanda de vínculo do tipo fusional, somada à falta de um elemento terceiro para separá-las.

No momento em que se tornam mães, estas mulheres trazem à tona aquela que foi a mãe de suas infâncias. Em conseqüência disto, mostram grande dificuldade em se separarem de seus filhos. O que a autora observa é que a mãe não consegue "largar" o filho que, por sua vez, não consegue renunciar ao desejo de vir a preenchêla. Nessa captura imaginária da criança pelo desejo da mãe, são criadas as condições para a eclosão de fobias, como a autora mostra em vários relatos clínicos.

Destaco o caso de Isabelle e Lea, onde a autora disseca a questão da fobia infantil, o desenvolvimento da fobia significando uma forma de "escapar do desejo por demais cativante de suas mães” (p. 133). 
R E V I S

LATINOAMERICANA

DE PSICOPATOLOGIA

F U N D A M E T A L

ano V, n. 2, jun/ 2002

Reportando-se novamente à função do serviço de neonatologia, Mathelin enfatiza que este período de hospitalização serve para que a criança possa se construir e construir sua mãe: “Mãe que, suficientemente construída, suportará a separação, indispensável ao nascimento do sujeito” (p. 147).

Nesse contexto, a hospitalização teria um efeito de prevenção, já que o discurso médico vem interromper o que parecia ser da ordem da maldição para a mãe. Um discurso que funcionaria como um "pedaço de pau na boca aberta do jacaré” (p. 147), proibindo o gozo da devoração.

Ao final do livro, a autora retoma o caso do Pequeno Hans e de Leonardo da Vinci para exemplificar histórias em que os filhos tornam-se presas do desejo materno, tendo como conseqüências a fobia e a imaturidade sexual.

No caso de Leonardo, ela destaca a lembrança infantil do abutre sobre seu berço, abrindo sua boca com o rabo e batendo várias vezes em seus lábios. A figura da mãeabutre representaria o excesso de paixão que o aprisionava.

Também o sorriso da Gioconda seria, para Leonardo, o reflexo de sua angústia e de sua perturbação diante das mulheres, assim como para o menino do Louvre. O que há de inquietante no sorriso da Gioconda? A angústia face ao desejo da mãe, face ao amor em forma de "possessão devastadora” (p. 20).

Diz Mathelin, no final do livro:

Encontramos com freqüência este quadro. Uma mãe não pode se desprender, por não ter encontrado seu pai, de uma outra mãe cujo gozo sem devastação não conhece limites. Aprisionada nesse corpo a corpo com ela, ela faz um filho sem nisso arriscar seu desejo de mulher por um homem e esse filho, de quem não se sabe muito bem quem é o pai (...), acha-se na mesma posição que Hans ou Leonardo. Ele ocupa um lugar designado do qual não pode se esquivar.

Podemos imaginar as conseqüências dramáticas se o filho, para quem o lugar pode ter sido designado desde antes do nascimento, acabar por nascer prematuramente, em perigo de morte, retirado da mãe. É nesta configuração que o papel do serviço de neonatologia será essencial, se aceitar situar-se como terceiro, se assumir seu papel "separador”. (p. 151)

Ricamente ilustrado com um grande número de casos clínicos, o livro é de leitura fácil, colocando o leitor, em alguns momentos, como que "dentro" do hospital, vivendo cada situação e podendo partilhar das angústias, dúvidas, dores e alegrias de um trabalho com crianças tão frágeis mas, em muitos casos, com uma enorme vontade de viver...

Uma leitura obrigatória para quem trabalha em Instituições, com equipes multidisciplinares, e recomendada a todo clínico, uma vez que coloca o lugar do analista como algo a ser constantemente reinventado. 